\title{
The roles of autophagy and thyroid hormone in the pathogenesis and treatment of NAFLD
}

\author{
Jin Zhou', Rohit A. Sinha' ${ }^{2}$ Paul M. Yen ${ }^{1,3}$ \\ ${ }^{1}$ Program of Cardiovascular and Metabolic Disorders, Duke-NUS Medical School, Singapore 169857, Singapore. \\ ${ }^{2}$ Department of Endocrinology, Sanjay Gandhi Postgraduate Institute of Medical Sciences, Lucknow 226014, India. \\ ${ }^{3}$ Department of Medicine Duke Molecular Physiology Institute, Duke University Medical Center, Durham, NC 27710, USA. \\ Correspondence to: Dr. Jin Zhou, Program of Cardiovascular and Metabolic Disorders, Duke-NUS Medical School, 8 College \\ Road, Singapore 169857, Singapore. E-mail: jin.zhou@duke-nus.edu.sg; Prof. Paul M. Yen, Program of Cardiovascular \& \\ Metabolic Disorders, Duke-NUS Medical School, 8 College Road, Singapore 169857, Singapore. \\ E-mail: paul.yen@duke-nus.edu.sg
}

How to cite this article: Zhou J, Sinha RA, Yen PM. The roles of autophagy and thyroid hormone in the pathogenesis and treatment of NAFLD. Hepatoma Res 2021;7:72. https://dx.doi.org/10.20517/2394-5079.2021.82

Received: 23 Jun 2021 First Decision: 24 Aug 2021 Revised: 31 Aug 2021 Accepted: 27 Sep 2021 Published: 5 Nov 2021

Academic Editor: Amedeo Lonardo Copy Editor: Yue-Yue Zhang Production Editor: Yue-Yue Zhang

\begin{abstract}
Non-alcoholic fatty liver disease (NAFLD) is the most prevalent chronic liver disorder worldwide. It comprises simple steatosis and non-alcoholic steatohepatitis (NASH), which can further progress to cirrhosis and hepatocellular carcinoma. The pathogenesis of NAFLD involves genetic, environmental, and endocrine factors, and several molecular mechanisms have been identified. In this review, we discuss the recent findings on the role of autophagy, in particular lipophagy and mitophagy, in hepatic lipid oxidation. We discuss the pre-clinical and clinical evidence suggesting that impairment of autophagy exacerbates NAFLD progression and restoration of autophagy exerts beneficial effects on NAFLD. We discuss how thyroid hormone (TH) simultaneously regulates lipophagy, mitophagy, and mitochondrial biogenesis to increase $\beta$-oxidation of fatty acids and reduce steatosis in the liver. Lastly, we discuss the recent clinical progress in using TH or thyromimetics in treating NAFLD/NASH.
\end{abstract}

Keywords: Autophagy, mitophagy, thyroid hormone, lipid oxidation, NAFLD

\section{INTRODUCTION}

Non-alcoholic fatty liver disease (NAFLD) is the most prevalent chronic liver disease. Its earliest manifestation is non-alcoholic fatty liver (NAFL) occurring in the absence of significant consumption of 
alcohol or other known causes of liver steatosis such as viral hepatitis and medication (e.g., tamoxifen, amiodarone, and methotrexate $)^{[1]}$. NAFL can progress to non-alcoholic steatohepatitis (NASH), which is characterized by progressive inflammation, hepatocyte death, and fibrosis ${ }^{[2]}$. The global prevalence of NAFLD is estimated to be $20 \%-40 \%{ }^{[3,4]}$, while the prevalence of NASH ranges between $1.5 \%$ and $6.45 \%{ }^{[5]}$ and is expected to rise over the next 20 years ${ }^{[6]}$. NASH now represents the fastest growing indication for liver transplantation in Western countries ${ }^{[]]}$.

NAFLD is highly associated with features of metabolic syndrome such as diabetes, obesity, and dyslipidemia. The presence of NASH and fibrosis are also strongly associated with increased risk of cardiomyopathy and arrhythmias, chronic kidney disease, sarcopenia, and other extrahepatic malignancies ${ }^{[8-10]}$. In addition, biopsy-confirmed fibrosis is associated with increased risk of mortality and liver-related morbidity in patients with NAFLD ${ }^{[1]}$. Currently, lifestyle modifications such as diet and exercise play important roles in the management of NASH since there are no FDA-approved drugs. However, several compounds now are undergoing Phase 3 clinical trials in patients with NASH, including farnesoid X receptor (FXR) agonist obeticholic acid (REGENERATE/NCT02548351), stearoyl-CoA desaturase 1 (SCD1) inhibitor aramchol (NCT04104321), C-C chemokine receptors type 2 (CCR2) and 5 (CCR5) dual antagonist cenicriviroc (AURORA/NCT03028740), glucagon-like peptide 1 (GLP-1) receptor agonist semaglutide (NCT04822181), and selective thyroid hormone receptor $\beta$ (THR $\beta$ ) agonist MGL-3196 (MAESTRO-NASH/NCT03900429).

NAFLD is a chronic and complex disease, and it has been postulated that "multiple parallel hits" may be involved in the molecular pathogenesis of NAFLD. There also are metabolic conditions associated with NAFLD/NASH (e.g., diabetes and hypothyroidism) which may predispose, or even play a pathogenic role, in NAFLD. In this review, we discuss the current controversy regarding the change in nomenclature of NAFLD to MAFLD to reflect the key role of metabolism in this condition. We also discuss the impairment of the autophagy in NAFLD, with a focus on the roles of lipophagy and mitophagy and their potential as "targets" to reduce steatosis by promoting lipid oxidation in NAFLD, particularly by thyroid hormone (TH). Finally, we review the clinical studies thus far supporting $\mathrm{TH}$ and its analogs as novel pharmacological agents for NAFLD/NASH treatment.

\section{NAFLD vs. MAFLD controversy}

Recently, it has been proposed that the old nomenclature "NAFLD" be replaced by metabolic dysfunctionassociated fatty liver disease (MAFLD) ${ }^{[12,13]}$. In this new system, the diagnosis of MAFLD is based on the presence of hepatic steatosis, in addition to one of the following three criteria: (1) obesity; (2) presence of Type 2 diabetes mellitus (T2DM); or (3) evidence of metabolic dysregulation ${ }^{[12,13]}$. It has been suggested that the new nomenclature and diagnostic criteria reflect the pathogenesis more accurately and emphasize the tight connection between this condition and metabolic dysfunction. However, the proposal to rename NAFLD to MAFLD still is controversial. Although MAFLD reflects some of the relevant risk factors for this liver disease, it has shortcomings since it does not distinguish between metabolic defects that have an etiological role for MAFLD and those that are consequences of $\mathrm{it}^{[14]}$. While the umbrella term "MAFLD" still covers a spectrum of disease stages, it lacks clear staging criteria to categorize disease severity making it difficult to employ this classification system to assess clinical progression. In addition, the elimination of "NASH" as a subtype could place several current Phase $2 \mathrm{~b}$ and 3 trails in jeopardy since these trials were designed using the old criteria for NASH to assess drug efficacy. Thus, without better understanding of the pathogenesis of NAFLD and improvements in classifying the patients, simply renaming the disease may not accelerate the discovery of biomarkers or drug development, even if national drug regulatory agencies decide to adopt the new nomenclature. 
Recently, several other suggestions for a better classification of patients with NAFLD have been proposed. Singh et al. ${ }^{[15]}$ proposed a "MEGA-D" classification of NAFLD in which NAFLD remains the umbrella entity and has new subgroups under it such as NAFLD-M (metabolic syndrome-associated NAFLD), NAFLD-E (environmental stressor-related NAFLD), NAFLD-G (genetic factor-associated NAFLD), NAFLD-A (bile acid dysregulation-related NAFLD), and NAFLD-D (gut dysbiosis-related NAFLD). Lonardo et al. ${ }^{[16]}$ proposed a "LED" classification in which the prefix "L" is for "liver" which mainly identifies the liver histological determinants, "E" is for common "extra-hepatic" manifestations such as metabolic and cardiovascular profiles, and " $\mathrm{D}$ " is for "determinants" in individual patients such as sex, menopause, and metabolic syndrome status, which may have epigenetic roles, and specific single nucleotide polymorphisms that could have genetic implications.

Currently, within the hepatology field, it is difficult to resolve the controversies surrounding the use of "NAFLD" vs. "MAFLD" or other proposed nomenclatures that try to consider and incorporate other key features of the liver disease within their terminology. Adopting new nomenclature is complicated further by the fact this field is rapidly advancing with new information on the genetic, metabolic, and cellular mechanisms of NAFLD. It would be appropriate and timely for an international consensus group comprised of academic, pharmaceutical, and regulatory members to decide whether a new nomenclature is warranted at this time and to agree upon the precise meanings of any new terminology that is adopted. In this review, we use NAFLD or NASH since they are still the most commonly used terms in the literature.

\section{Autophagy in NAFLD}

Autophagy: the process

Macroautophagy, referred as autophagy hereafter, is a highly conserved autophagosome- and lysosomedependent degradation process. Autophagy is essential for cellular function during normal physiological conditions and is further induced as an adaptive response to different stresses such as starvation or hypoxia. Autophagy begins by the formation of cup-shaped structures called "phagophores" that originate from specific endoplasmic reticulum (ER) membrane domains called "phagophore assembly sites (PASs)". Interestingly, in addition to giving rise to phagophores, PASs can also serve as membrane contact sites that generate nascent ER-mitochondria and ER-plasma membrane structures ${ }^{[17]}$. During the elongation and expansion of phagophores into spheres, cytoplasmic materials and damaged organelle remnants become autophagic cargo engulfed within the inner membrane. These isolation membranes eventually seal to form an autophagosome with a double-membraned structure. Upon further maturation, the autophagosomes then travel along microtubules to lysosomes, whereupon the outer membranes of autophagosomes fuse with lysosomes to form autolysosomes. Afterwards, single membrane structures release their cargo into lysosomes for degradation by resident hydrolases. Cargo degradation produces small molecules such as amino acids, phospholipids, simple carbohydrates, and fatty acids, which are released subsequently from lysosomes into the cytoplasm for the cell to recycle and reuse ${ }^{[18]}$. Autophagy also serves as one of the main mechanisms to remove damaged organelles such as mitochondria, peroxisomes, lysosomes, and $\mathrm{ER}^{[19]}$ and degrade them into small molecules that can serve other cellular functions or lead to resynthesis of organelles or formation of new structures within the cell. There are approximately 20 autophagy-related (ATG) proteins that sequentially participate in the formation of phagophores and their maturation to autophagosomes that fuse with lysosomes to form autolysosomes ${ }^{[20]}$.

Lipophagy

During starvation conditions, autophagy plays an important role in the utilization of stored lipids that are critical for supplying fuel to generate ATP. Autophagic mobilization of lipid droplets (lipophagy) was initially discovered in hepatocytes and subsequently in other cell types ${ }^{[21]}$. Singh et al ${ }^{[21]}$ showed that autophagic delivery of triglycerides from lipid droplets (LDs) to their hydrolysis in autolysosomes was an 
essential mechanism for hepatocytes to convert triglycerides stored in LDs to free fatty acids (FFAs) that subsequently underwent oxidation in mitochondria to generate ATP. Additionally, decreased lipid oxidation and increased steatosis occurred in cultured hepatocytes as well as in mouse liver when autophagy was inhibited, suggesting that this was a key mechanism for converting stored triglycerides into FFAs in the liver ${ }^{[21]}$. Another form of autophagy that utilizes heat shock proteins is chaperone-mediated autophagy (CMA), which degrades proteins (perilipin 2 and 3) located at LD membranes to initiate lipophagy ${ }^{[22]}$. During energy stress, AMPK phosphorylates choline kinase $\alpha 2$ (CHKa2) at Ser279, while KAT5 acetylates $\mathrm{CHK} \alpha 2$ at Lys247. These modifications activate $\mathrm{CHK} \alpha 2$ and phosphorylate LD membrane proteins, perilipin 2 (PLIN2) and 3 (PLIN3). The phosphorylation of PLIN2/3 dissociates PLIN2/3 from LD for CMA-mediated degradation ${ }^{[23]}$.

Lipophagy activation also requires recruitment of autophagy machinery to the $\mathrm{LD}$, a process that is abolished in PLIN3 knockdown cells. PLIN3 indeed directly interacts with autophagy proteins Fip200 and Atg $16 \mathrm{~L}^{[24]}$. IFGGA2 is an immunity-related GTPase which co-localizes with ATGL and LC3B on LDs when animals are fed a high fat diet (HFD). Overexpression of IFGGA2 increases association of LC3B with LDs and decreases lipid content ${ }^{[25]}$. Fasting-induced fibroblast growth factor-21 activates autophagy and lipid degradation through Jumonji-D3 histone demethylase mediated epigenetic changes ${ }^{[26]}$. Natural and pharmacologic ligands for nuclear receptors, such as THR, PPAR $\alpha$, and FXR, as well as $\beta$-adrenergic receptors, can also regulate lipophagy ${ }^{[27-30]}$, highlighting the prominent role for endocrine regulation of this cellular process. Fenofibrate, a PPAR $\alpha$ agonist, activates lipophagy and reduces hepatic fat accumulation through induction of lysosomal $\mathrm{Ca}^{2+}$ release, calcineurin activation, and transcription factor EB (TFEB) and TFE3 dephosphorylation ${ }^{[31]}$. Moreover, we recently showed that a thyromimetic and two PPAR $\alpha$ agonists improve hepatosteatosis in the glycogen storage disease GSD $1 \mathrm{a}^{[32-34]}$. Additionally, natural compounds such as green tea polyphenol or caffeine that stimulate autophagy also reduce hepatosteatosis ${ }^{[35,36]}$. Taken together, these data suggest that inducing and enhancing lipophagy could be novel strategies for treating NAFLD.

\section{Mitophagy}

Mitochondria serve as energy hubs for both oxidation of fatty acids and ATP production through oxidative phosphorylation (OXPHOS). The latter process also generates reactive oxygen species (ROS) that can impair mitochondrial function and integrity to cause mitochondrial depolarization and loss of membrane potential. In mammalian cells, the loss of membrane potential is a strong stimulator that triggers mitophagy ${ }^{[37]}$. Mitophagy is a critical quality control process to eliminate mitochondria damaged by ROS and prevent the initiation of an inflammatory response or apoptosis ${ }^{[38]}$.

Several types of mitophagy are described in the literature ${ }^{[39]}$; however, PINK1-PARKIN-mediated mitophagy is the most extensively characterized mechanism. PINK1, a Ser/Thr kinase, requires a normal mitochondrial membrane potential to be imported into the inner mitochondrial membrane (IMM). Thus, PINK1 serves as depolarization sensor. Loss of membrane potential prevents PINK1's IMM translocation, leaving it on the outer mitochondrial membrane (OMM) where it is activated subsequently by autophosphorylation ${ }^{[40-42]}$. Active PINK1 phosphorylates several other substrates such as ubiquitin and PARKIN, an E3-ubiquitin ligase that increases the polyubiquitination of OMM proteins ${ }^{[4]}$. Their polyubiquitin chains are recognized by autophagy receptor proteins such as 662 or optneurin that also contain LC3 interaction regions (LIRs) to recruit the key ATG protein, LC3, to promote membrane sequestration of ubiquitinated mitochondrial proteins into autophagosomes. 
Several PINK1-PARKIN-independent pathways for mitophagy induction have also been identified ${ }^{[43]}$, including FUN14 domain containing 1 (FUNDC1)-mediated autophagy. FUNDC1 is an OMM protein that contains a LIR facing the cytosol ${ }^{[44]}$. Under normal physiological conditions, FUNDC1 is phosphorylated at Tyr18 and Ser13, which reduces its interaction with LC3. However, during cellular stress such as hypoxia, mitochondrial phosphatase PGAM family member 5 dephosphorylates FUNDC1 at Tyr 18 and Ser $13^{[45]}$. Concomitant phosphorylation of FUNDC1 at Ser17 by unc-51-like autophagy activating kinase 1 (ULK1) causes FUNDC1 to become activated and enable it to interact with LC3 to promote mitophagy ${ }^{[4,46]}$.

\section{Dysregulation of autophagy in NAFLD}

Patients with NAFLD have impaired autophagy that typically is manifested by accumulation of both LC3BII and p62 in hepatic cells ${ }^{[47]}$. Although the increases in LC3B-II and p62 suggest there is a late-stage block in autophagy, multiple steps may be involved [Figure 1]. First, there can be decreased autophagosome/lysosome fusion due to increased expression of rubicon, a negative regulator of autophagosome-lysosome fusion ${ }^{[48]}$, or decreased expression and/or function of the autophagsome/lysosome fusion SNARE complex. Lysosomal function can also be impaired due to decreased levels of lysosomal proteases, leading to decreased lysosomal degradation ${ }^{[49]}$. Additionally, autophagosome biogenesis itself can be impaired preceding or in conjunction with late-stage autophagy block. Zhang et al.$^{[50]}$ found that nuclear localization of the master transcriptional regulator for lysosomal biogenesis, TFEB, was negatively associated with steatosis, suggesting that progression of NAFLD from NAFL to NASH can occur through multiple mechanisms.

Rodent models of NAFLD employing high fat content diets recapitulate the main features of NAFLD observed in human ${ }^{[21,51]}$. Inhibition of autophagy through genetic deletion of key autophagic proteins $\operatorname{Atg} 7^{[52]}$ and $\operatorname{Atg} 14^{[53]}$ in hepatocytes further worsened the hepatic phenotype in mouse models of NAFLD. In contrast, restoration of autophagy by overexpression of $\operatorname{Atg}_{14}{ }^{[53]}, \operatorname{TFEB}^{[0,51]}$, or deletion of rubicon ${ }^{[48]}$ improved hepatic steatosis and injury, as well as attenuated cellular stress. Furthermore, deletion of Atg5 in myeloid cells promoted proinflammatory macrophage polarization and increased the inflammatory response in $\mathrm{NAFLD}^{[54]}$. Recent data also showed that impaired mitophagy led to formation of megamitochondria that could contribute to liver injury during NAFLD ${ }^{[55]}$. These studies demonstrated that impaired autophagy is one of the main molecular mechanisms that contribute to NAFLD progression. Moreover, restoration of autophagy improves the NASH phenotype and thus could be a novel strategy to treat NAFLD.

Recent studies also identified novel regulators of autophagy in the context of NAFLD. Liver X receptor alpha (LXR $\alpha$ ) and sterol regulatory element-binding protein (SREBP)- $1 \mathrm{C}$ are some of the main transcription factors that regulates lipogenesis. Their expression was upregulated in a rodent model of NAFLD and patients with NAFLD ${ }^{[56]}$. Kim et al..$^{[57]}$ showed that LXR $\alpha$ inhibits autophagy through inducing let-7a and miR-34a transcription, which suppress ATG4B and Rab-8b. Furthermore, NAFLD patients had elevated let$7 \mathrm{a}$ and miR-34a levels with simultaneous decreases in ATG4B and Rab-8B levels ${ }^{[57]}$. Nguyen et al. ${ }^{[58]}$ showed that SREBP-1C-induced miR-216a expression resulted in reduced cystathionine gamma-lyase and hepatic $\mathrm{H} 2 \mathrm{~S}$ levels, sulfhydration-dependent activation of ULK1, and autophagy flux and lipid degradation. In addition, the expression of ULK1 was downregulated in a mouse model of NAFLD and patients with NAFLD $^{[59]}$. Increased Mir214-3p and decreased Hnf4a expression led to reduced Ulk1 levels in a mouse model of NAFLD ${ }^{[59]}$. Hepatic expression of Acyl-CoA oxidase 1, the enzyme that catalyzes the first step in peroxisomal $\beta$-oxidation, was upregulated by HFD feeding; increased hepatic peroxisomal $\beta$-oxidation derived acetyl-CoA, raptor acetylation, and activation of mTORC1; and led to decreased autophagy and increased hepatic triglycerides ${ }^{[60]}$. 


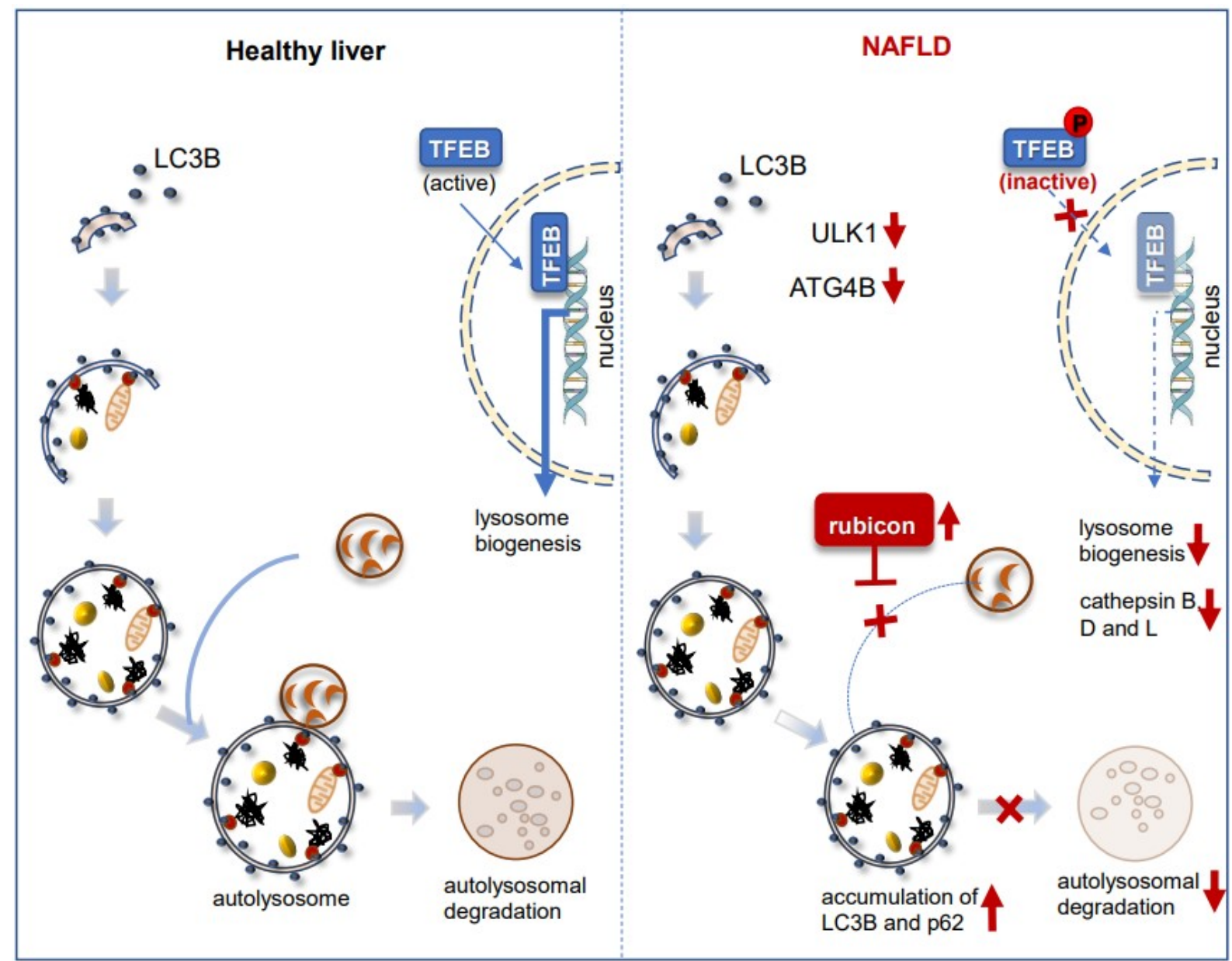

Figure 1. Defects in autophagy in patients with NAFLD. Several steps in autophagy process are affected in patients with NAFLD. First, there is decreased levels of ULK1 and ATG4B. Second, autophagosome/lysosome fusion is decreased due to increased expression of rubicon. Third, decreased nuclear translocation of TFEB, lysosomal biogenesis and lysosomal protease levels, leads to decreased lysosomal degradation and accumulation of LC3B-II and p62. NAFLD: Non-alcoholic fatty liver disease; ULK1: unc-51-like autophagy activating kinase 1; TFEB: transcription factor EB.

It is generally believed that lipotoxicity is one of the major triggers for hepatic inflammation and hepatocytes death in patients with NAFLD as disease progresses. Interestingly, emerging evidence also suggests that the stress responses activated in NAFLD also regulate autophagy. Spliced X-box binding protein 1, a key factor that promotes unfolded protein response in response to the ER stress, directly upregulates the expression of $\mathrm{TFEB}^{[61]}$. Thioredoxin interacting protein, a key mediator of cellular stress, directly interacts with and positively regulates AMPK phosphorylation to inhibit mTORC1, leading to TFEB activation $^{[62]}$. In contrast, mixed lineage kinase domain-like, a pseudokinase in the necroptotic pathway of programmed cell death, is upregulated by lipotoxic lipid palmitic acid (PA), translocates to autophagosome membrane, and blocks its fusion with lysosome ${ }^{[63]}$. PA also induces stimulator of interferon response cGAMP interactor 1 (STING1), which interacts with several components of the mTORC1 complex and activates mTORC1 to inhibits autophagy ${ }^{[64]}$.

\section{TH effects on impaired autophagy in NAFLD}

Thyroid hormone (TH) is essential for important physiological processes such as development, growth, and metabolism in most higher organisms. Thyroxine $\left(\mathrm{T}_{4}\right)$ and triiodothyronine $\left(\mathrm{T}_{3}\right)$ are the two major 
circulating THs synthesized and secreted by the thyroid gland. However, $\mathrm{T}_{3}$ is the more biologically active form, and its concentration in circulation is much lower than $\mathrm{T}_{4}$. Both $\mathrm{T}_{4}$ and $\mathrm{T}_{3}$ enter cells through transporters that belong to the monocarboxylate transporter 8, organic-anion-transporting polypeptide 1 , and the L-type amino acid transporter families ${ }^{[65,66]}$. The deiodinases, deiodinase 1 (DIO1) and deiodinase 2 (DIO2), convert intracellular $\mathrm{T}_{4}$ to $\mathrm{T}_{3}^{[67]}$, while $\mathrm{DIO}_{3}$ converts $\mathrm{T}_{3}$ to the inactive reverse triiodothyronine $\left(\mathrm{rT}_{3}\right)$. Thyroid hormone receptors (THRs) are members of the nuclear hormone receptor family and are comprised of two major isoforms, THR $\alpha 1$ and THR $\beta 1$, encoded by THRA and THRB genes, respectively. THR $\alpha 1$ is the predominant isoform in bone, cardiac, and skeletal muscle and the gastrointestinal tract, whereas THR $\beta 1$ is the predominant isoform in the liver and kidney ${ }^{[68]}$. Intracellular $\mathrm{T}_{3}$ binds to nuclear THRs that interact with TH response elements located within the promoters or enhancer regions of target genes and recruit co-activators and RNA polymerase II to regulate transcription. Thus, THRs act as ligandinducible transcription factors ${ }^{[6]]}$.

In the liver, $\mathrm{TH}$ regulates genes involved in a diverse range of metabolic pathways, including hepatic lipogenesis, lipid oxidation, cholesterol homeostasis, and gluconeogenesi $\mathrm{s}^{[69]}$. The transcriptional regulation of hepatic metabolism by TH is reviewed elsewhere ${ }^{[70-72]}$. TH also increases lysosomal acid lipase expression and lysosomal activity ${ }^{[6,73]}$. Sinha et al..$^{[27]}$ also showed that $\mathrm{TH}$ is a potent stimulator of hepatic lipophagy in cultured hepatic cells and mouse liver. Furthermore, inhibition of autophagy abolished TH-induced hepatic $\beta$-oxidation and ketogenesis in mice ${ }^{[27]}$. Thus, TH-induced lipophagy is essential for mobilizing hepatic triglycerides and releasing free fatty acids for mitochondrial $\beta$-oxidation. Indeed, acute TH stimulation utilizes lipophagy as the predominant mechanism for hydrolysis of triglycerides from $\mathrm{LD}$, whereas chronic TH stimulation increases hepatic lipase gene expression in addition to autophagy.

$\mathrm{T}_{3}$ also promotes hepatic mitophagy, as evidenced by increased engulfment of mitochondria inside autophagosomes and autolysosomes in electron micrographs ${ }^{[74]} . \mathrm{T}_{3}$ increases the expression and activation of ULK1, which promotes Drp1-mediated mitochondrial fission, FUNDC1 activation and interaction with $\mathrm{LC} 3 \mathrm{~B}$, and p62 translocation to mitochondria in hepatic cells ${ }^{[7,75]} \cdot \mathrm{T}_{3}$-mediated induction of mitophagy is essential for its stimulation of mitochondrial $\mathrm{OXPHOS}^{[7]}$. Concurrently, $\mathrm{T}_{3}$ also increases mitochondrial biogenesis $^{[75]}$. Thus, $\mathrm{T}_{3}$ generates and maintains an intracellular pool of healthy mitochondria to increase mitochondrial activity and $\beta$-oxidation of fatty acids by increasing the rates of mitophagy and mitochondrial synthesis, i.e., mitochondrial turnover.

The activation of the autophagy/mitophagy pathway by $\mathrm{T}_{3}$ is mediated by mitochondrial ROS production. Indeed, in cultured hepatic cells, TH simultaneously increases mitochondrial OXPHOS, mitochondrial ROS generation, and membrane potential. Thus, low levels of $\mathrm{T}_{3}$-induced ROS ( $40 \%$ increase compared to untreated cells) are not toxic but actually serve beneficial roles in cells (hormesis) by acting as signaling molecules to increase cellular $\mathrm{Ca}^{2+}$ levels and activate CAMKK2-AMPK signaling ${ }^{[7]}$. Activated AMPK then directly phosphorylates ULK1 to induce phagosome formation for autophagy as well as promotes ULK1 translocation to mitochondria to increase mitophagy [Figure 2] ${ }^{[76-79]}$.

Interestingly, $\mathrm{T}_{3}$ also induces the expression of several proteins that contribute to the induction of lipophagy and mitophagy/mitochondrial biogenesis. Estrogen-related receptor $\alpha(E R R \alpha)$ is an orphan nuclear receptor that is transcriptionally induced by $\mathrm{T}_{3}$ in an PGC1 $\alpha$-dependent manner. Induction of ERR $\alpha$ by $\mathrm{T}_{3}$ is essential for the latter's effects on mitochondrial biogenesis, fission, mitophagy, and induction of ULK1 expression ${ }^{[75]}$. Mediator complex subunit 1 (MED1) is a major component of the multi-subunit mediator complex that bridges nuclear receptor bound to promoter with RNA polymerase II and serves as a coactivator to increase transcription of target genes regulated by nuclear receptors ${ }^{[80]}$. MED1 regulates 


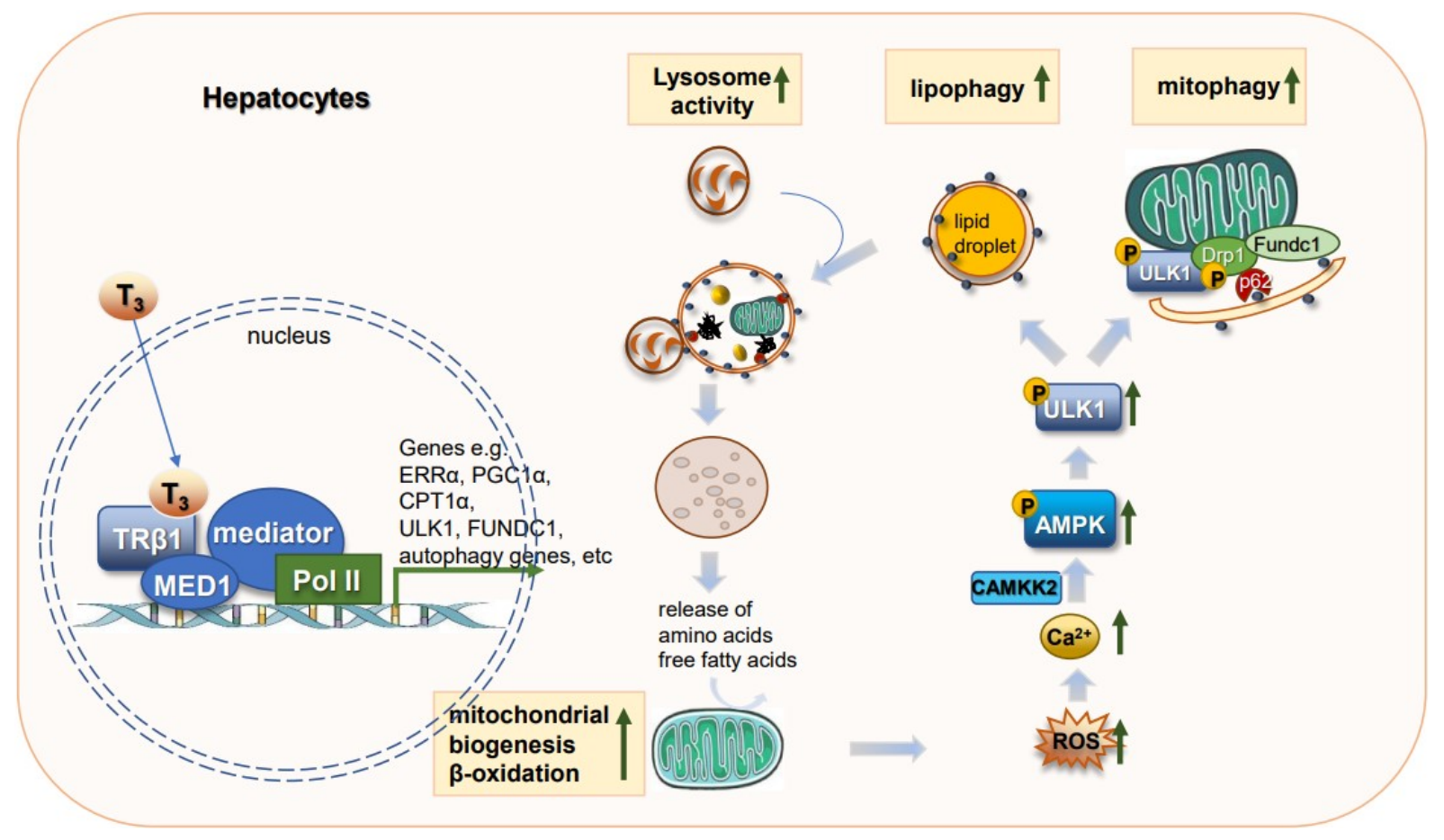

Figure 2. TH effects on hepatic autophagy. TH increases transcription of genes involved in autophagy, mitochondrial biogenesis, and lipid metabolism. Increases in mitochondrial $\beta$-oxidation of fatty acids increase ROS which then serve as signaling molecules to activate the CAMKK2-AMPK-ULK1 pathway to stimulate lipophagy. Lipophagy mobilizes lipolysis of triglycerides stored in LDs as free fatty acids that act as fuel for mitochondrial utilization. ROS also activates mitophagy to remove damaged mitochondria. TH: Thyroid hormone; ROS: reactive oxygen species; LDs: lipid droplets; CAMKK2: calcium/calmodulin dependent protein kinase kinase 2; AMPK: AMPactivated protein kinase; ULK1: unc-51 like autophagy activating kinase 1.

transcription of autophagic and mitochondrial genes to increase autophagy/lipophagy, mitochondrial OXPHOS, and $\beta$-oxidation of fatty acids ${ }^{[81]}$. Since MED1 directly interacts with THR bound to the promoter region $^{[82]}$, it is necessary for transcriptional regulation of $\mathrm{T}_{3}$-induced genes involved in autophagy/lipophagy and mitochondrial OXPHOS $^{[81]}$. $\mathrm{T}_{3}$ also increased the expression of $\beta$-trophin (C19orf80; also known as ANGPTL8), a protein that is critical for TH-mediated induction of hepatic lipophagy and TAG hydrolysis ${ }^{[83]}$.

Apart from $\mathrm{T}_{3}$, other TH metabolites such as $\mathrm{T}_{2}$ also mediate hepatic autophagy via induction of TFE3 and TFEB transcription factors to reduce hepatic steatosis in rodent models of NAFLD ${ }^{[84]}$.

\section{TH effects on inflammasome formation and inflammation}

Both TH and mitophagy inhibit the overactivation of NLRP3 inflammasome. NLRP3 inflammasome is an intracellular multiple complex activated in response to pathogen-associated molecular patterns or damagedassociated molecular patters to increase secretion of pro-inflammatory cytokines. NLRP3 inflammasome consists of a sensor protein NLRP3, an adaptor protein ASC, and an effector protein caspase 1. NLRP3 recognition of its activator triggers the assembly of inflammasomes and activation of caspase 1 , resulting in the cleavage of pro-interleukin (IL)- $1 \beta$ and pro-IL-18 to matured IL-1 $\beta$ and IL-18. Several signals activate NLRP3 inflammasome, e.g., efflux of potassium ions, lysosomal disruption, metabolic changes, and mitochondrial ROS and $\mathrm{mtDNA}^{[85,86]}$. Although inflammasome activation is one of the first lines of host defense, excessive activation can lead to inflammatory diseases such as NAFLD ${ }^{[87]}$. One of the molecular mechanisms that prevent NLRP3 inflammasome overactivation is removal of damaged mitochondria by 
mitophagy. In macrophages, $\mathrm{p} 62$ is upregulated by NF- $\mathrm{kB}$, which is recruited to damaged mitochondria and mediates mitophagy. Loss of this pathway resulted in exacerbated LPS-induced liver inflammation and damage. Thus, the NF-kB-p62-mitophagy pathway serves an intrinsic regulatory mechanism to prevent the overactivation of NLRP3 inflammasomes ${ }^{[88]}$. Autophagy also prevents excessive NLPR3 inflammasome activation through degradation of individual NLRP3 components such as ASC or NLRP3, or the entire NLRP3 inflammasome itself ${ }^{[89]}$.

$\mathrm{T}_{3}$ suppresses ischemia-reperfusion-induced hepatic NLRP3 inflammasome activation in an AMPKdependent manner ${ }^{[90]}$. THRs are expressed in macrophage cell lines ${ }^{[91]}$, and $\mathrm{T}_{3}$ negatively regulates NLRP3 inflammasome activation ${ }^{[92]}$. $\mathrm{T}_{3}$ enhances the expression of miRNAs miR-30, -133 , and $-144^{[93]}$, which inhibit the pro-inflammatory signals by downregulation of fast apoptosis signal ligand ${ }^{[94]}$. $\mathrm{T}_{3}$ downregulates the expression miR-31, -155 , and $-222^{[93]}$, to increase the gene and protein expression of superoxide dismutase 1 (SOD1) and $\mathrm{SOD}_{2}{ }^{[95]}$, which then decrease ROS levels and prevent excessive activation of the NLRP3 inflammasome. In addition, $\mathrm{T}_{3}$ downregulates the Toll-like receptor 4 (TLR4)/NF- $\kappa \mathrm{B}$ pathway to decrease inflammation ${ }^{[96,97]}$.

\section{Intrahepatic TH signaling is impaired in patients with NAFLD}

Several epidemiological studies have suggested that patients with NAFLD have increased prevalence of overt hypothyroidism and subclinical hypothyroidism ${ }^{[98,99]}$. Likewise, patients with overt and subclinical hypothyroidism have increased prevalence of $\mathrm{NAFLD}^{[100,101]}$. In healthy liver, hepatocytes have high DIO1 expression and stromal cells show low expression of DIO3. However, this expression pattern reverses in patients with advanced NASH, as evidenced by decreased DIO1 expression in hepatocytes and increased DIO3 expression in stromal cells ${ }^{[102]}$. These changes in expression of deiodinases during late NASH lower intrahepatic $\mathrm{T}_{3}$ concentration, either by decreased conversion from $\mathrm{T}_{4}$ to $\mathrm{T}_{3}$ or by higher conversion of $\mathrm{T}_{3}$ to $\mathrm{rT}_{3}$. The circulating $\mathrm{rT}_{3}$ level was increased in patients with $\mathrm{NASH}$, providing further evidence supporting the decrease in DIO1 activity during $\mathrm{NASH}^{[102]}$. Similar findings were also seen in rats fed a MCD (methionine/choline deficient) diet to induce NASH. Although their circulating $\mathrm{T}_{3}$ levels remained unchanged, hepatic DIO1 expression and intrahepatic $\mathrm{T}_{3}$ concentration decreased ${ }^{[103]}$. Recently, Bruinstroop showed that, although DIO1 levels were decreased in advanced NASH, there was a compensatory increase in DIO1 expression during hepatosteatosis (early NAFLD) in mice fed a Western diet with fructose ${ }^{[104]}$. Thus, the expression and activity of DIO1 may change as NASH progresses.

There is emerging evidence that impaired TH signaling in hepatic cells is associated with increased fibrosis in NAFLD. Tahara et al. ${ }^{[105]}$ showed that, among patients with NAFLD, significantly more patients with subclinical hypothyroidism had higher scores of a non-invasive marker of liver fibrosis, FIB-4 index, than patients with euthyroidism and NAFLD. Manka et al. ${ }^{[106]}$ found low free circulating $\mathrm{T}_{3}$ was associated with increased liver stiffness measured by transient elastography (Fibroscan). These findings suggest the possibility that decreased circulating $\mathrm{T}_{3}$ and/or intrahepatic $\mathrm{T}_{3}$ might promote hepatic fibrosis. In this connection, pre-clinical studies suggested TH may have an antifibrotic role since $\mathrm{TH}$ and the thyromimetic sobetirome were able to reduce lung fibrosis ${ }^{[107]}$. This anti-fibrotic effect likely was associated with the ability of TH to increase mitochondrial activity and mitophagy since TH did not decrease lung fibrosis in PGC1 $\alpha^{-}$ or PINK1-knockout mice ${ }^{[107]}$. Alonso-Merino et al. ${ }^{[108]}$ previously showed that $\mathrm{TH}$ decreased fibrosis in skin and lung injury models by stimulating THR interaction with TGF $\beta$-induced transcription factors such as SMAD3 and SMAD4. This interaction led to decreased SMAD phosphorylation and its binding to promoters of SMAD target genes involved in fibrosis ${ }^{[108]}$. 


\section{Clinical trials of $T_{4}$ and thyromemetics in patients with NAFLD/NASH}

To determine the clinical efficacy of TH for the treatment for hepatosteatosis, we treated 20 male euthyroid patients with T2DM and steatosis with low-dose $\mathrm{T}_{4}{ }^{[103]}$. We measured the change in intrahepatic lipid content by proton magnetic spectroscopy (MRI) before and after $\mathrm{T}_{4}$ treatment as the primary outcome measure. Patients were treated with daily doses of $\mathrm{T}_{4}$ determined by titration to a thyroid-stimulating hormone level between 0.34 and $1.7 \mathrm{mIU} / \mathrm{L}$. After patients were treated with $\mathrm{T}_{4}$ for 16 weeks, we found that intrahepatic lipid content decreased by $12 \%( \pm$ SEM, 26\% $)$ relative to baseline $(P=0.046)$. Moreover, atrial arrhythmia developed only in one patient. Thus, our study demonstrated low-dose $\mathrm{T}_{4}$ was a safe and effective short-term therapy for hepatosteatosis in man [Table 1].

Resmetirom (MGL-3196) is an orally active, selective THR $\beta 1$ agonist developed originally to treat obesity and hypercholesterolemia. To assess its efficacy as a treatment for NASH, adult patients with biopsy-proven NASH (fibrosis stages 1-3) and hepatic fat fraction of at least 10\% at baseline when assessed by MRI-proton density fat fraction (MRI-PDFF) were treated with MGL-3196 (80 mg once a day) for 36 weeks in a randomized, double-blind, placebo-controlled Phase 2 clinical trial (NCT02912260) ${ }^{[109]}$. The primary endpoint of the study measured the relative change in hepatic fat content in patients receiving MGL-3196 compared with those receiving placebo at Week 12. A secondary endpoint was NASH resolution based upon NASH Activity Score (NAS) of histology at 36 weeks. MGL-3196-treated patients showed a relative reduction of hepatic fat content when compared with placebo-treated patients at Week 12 [-32.9\% MGL$3196(n=78)$ vs. $-10.4 \%$ placebo $(n=38) ; P<0.0001]$, and more patients treated with MGL-3196 had a $>2$ point NAS reduction in histology of liver biopsy samples than patients treated with placebo (56\% MFL-3196 vs. $32 \%$ placebo; $P<0.024$ ). The levels of several serum markers for fibrosis were reduced in patients treated with MGL-3196; however, there were no significant differences observed in the amount of histological liver fibrosis between the MGL-3196 and placebo-treated patients ${ }^{[109]}$. Of note, this study had limitations since it was not adequately powered and the duration of the study may not have been long enough to evaluate changes in fibrosis. Currently, there is a large multicenter Phase 3 study aiming to enroll 2000 participants for evaluating the efficacy of MGL-3196 treatment for NASH (MAESTRO-NASH/NCT03900429). The primary outcome measure is resolution of NASH based upon histology of liver biopsies in non-cirrhotic NASH patients with stage 2 or 3 fibrosis after one-year treatment. Study participants will be monitored for long-term adverse outcome events such as all-cause mortality, cirrhosis, and other significant liver-related parameters.

VK2809 (formerly known as MB07811) is a pro-drug that undergoes first-pass hepatic extraction and cytochrome P450 cleavage to generate a negatively charged thyroid THR $\beta$ agonist, VK2809A (formerly known as MB07344 $)^{[110]}$. VK2809 is highly liver-specific and is rapidly eliminated in the bile ${ }^{[111]}$. VK2809 reduced hepatosteatosis in mouse models of NAFLD ${ }^{[12]}$ and glycogen storage disease type Ia (GSD-Ia), an inherited metabolic liver disease that can develop many similar hepatic features as NAFLD ${ }^{[33]}$. In the mouse model of GSD1a, VK2809 treatment decreased hepatic lipid content through its simultaneous restoration of autophagy, mitochondrial biogenesis, and $\beta$-oxidation of fatty $\operatorname{acids}^{[33]}$. A Phase $2 \mathrm{~b}$, randomized, doubleblind, placebo-controlled, multicenter clinical trial is currently underway to assess the efficacy and safety of VK2809 in patients with NASH (VOYAGE/NCT04173065) $)^{[113]}$. This study will enroll 337 participants with biopsy-proven NASH and divide them into treatment groups receiving 0, 1.0, 2.5, 5.0, or $10 \mathrm{mg}$ VK2809 orally once a day. The primary outcome measure is the change in fat content (assessed by MRI-PDFF) from baseline to 12 weeks in VK2809- vs. placebo-treated subjects. The secondary outcome measure is the percentage of drug- $v$ s. placebo-treated subjects who had significant improvement of their NASH based upon histology of liver samples after one year of treatment. 
Table 1. Clinical trials of thyroid hormone, thyroid hormone analogues in patients with NAFLD

\begin{tabular}{|c|c|c|c|c|c|}
\hline \multicolumn{6}{|l|}{ Completed studies } \\
\hline Compound & Treatment regimen & Liver function & Steatosis & NASH resolution & Fibrosis \\
\hline Levothyroxine $^{[104]}$ & $\begin{array}{l}20 \text { male patients with type } 2 \text { diabetes } \\
\text { and steatosis ( } 4 \text { months titrated to a } \\
\text { TSH 0.34-1.70 IU/L, median dose } \\
18.75 \mu \mathrm{g} / \text { day }\end{array}$ & $A S T, A L T=$ & Liver fat (H-MRS) $\downarrow$ & NA & NA \\
\hline $\begin{array}{l}\text { VK2809 } 9^{[114]} \text { meeting } \\
\text { abstract } \\
\text { (NCT02927184) }\end{array}$ & $\begin{array}{l}24 \text { patients with primary } \\
\text { hypercholesterolemia and NAFLD }(3 \\
\text { months, } 10 \mathrm{mg} \text { every day or every other } \\
\text { day }\end{array}$ & $\mathrm{AST}, \mathrm{ALT} \downarrow$ & Liver fat (MRI-PDFF) $\downarrow$ & NA & NA \\
\hline $\begin{array}{l}\text { MGL-3196 } 6^{[110]} \\
(\text { NCTO2912260) }\end{array}$ & $\begin{array}{l}84 \text { patients with biopsy confirmed } \\
\text { NASH (fibrosis stages } 1-3) \text { ( } 9 \text { months, } \\
40-80 \mathrm{mg} \text { daily) }\end{array}$ & AST, ALT $\downarrow$ & Liver fat (MRI-PDFF) $\downarrow$ & NAS score $\downarrow$ & Not significant by liver histology \\
\hline \multicolumn{6}{|l|}{ Recruiting } \\
\hline Compound & Treatment regimen & $\begin{array}{l}\text { Estimated } \\
\text { participants }\end{array}$ & Primary outcome & \multicolumn{2}{|c|}{ Secondary outcome } \\
\hline $\begin{array}{l}\text { VK2809 } \\
\text { (NCT04173065) }\end{array}$ & $\begin{array}{l}\text { 52-week VK2809 administration ( } 1,2.5, \\
5 \text {, or } 10 \mathrm{mg} \text { daily) in patients with biopsy } \\
\text { proven NASH with fibrosis }\end{array}$ & 337 & $\begin{array}{l}\text { Relative change in liver fat content from baseline to Week } 12 \text { in } \\
\text { subjects treated with VK2809 compared to the change in } \\
\text { subjects treated with placebo }\end{array}$ & \multicolumn{2}{|c|}{$\begin{array}{l}\text { Proportion of subjects with resolution of steatohepatitis on overall } \\
\text { histopathological reading and no worsening of liver fibrosis on } \\
\text { NASH fibrosis score }\end{array}$} \\
\hline $\begin{array}{l}\text { MGL-3196 } \\
\text { (NCT04197479) }\end{array}$ & $\begin{array}{l}\text { 52-week MGL-3196 administration ( } 80 \\
\text { or } 100 \text { mg daily) to patients with } \\
\text { NAFLD }\end{array}$ & 700 & $\begin{array}{l}\text { The effect of MGL-3196 vs. placebo on the incidence of } \\
\text { adverse events }\end{array}$ & \multicolumn{2}{|c|}{$\begin{array}{l}\text { The effect of MGL-3196 vs. placebo on the percentage changes in } \\
\text { LDL-C, ApoB, hepatic fat fraction, TGs, and PRO-C3 }\end{array}$} \\
\hline $\begin{array}{l}\text { MGL-3196 } \\
\text { (NCT04951219) }\end{array}$ & $\begin{array}{l}\text { 52-week MGL-3196 administration ( } 80 \\
\text { or } 100 \text { mg daily) to patients with } \\
\text { NAFLD }\end{array}$ & 1000 & $\begin{array}{l}\text { The effect of MGL-3196 vs. placebo on the incidence of } \\
\text { adverse events }\end{array}$ & \multicolumn{2}{|c|}{$\begin{array}{l}\text { Percentage change in the hepatic fat fraction from baseline at week } \\
16 \text { and 52; percentage change in LDLC from baseline at week } 28\end{array}$} \\
\hline $\begin{array}{l}\text { MGL-3196 } \\
\text { (NCT03900429) }\end{array}$ & $\begin{array}{l}\text { 52-week MGL-3196 administration ( } 80 \\
\text { or } 100 \mathrm{mg} \text { daily) to patients with NASH } \\
\text { and fibrosis }\end{array}$ & 2000 & $\begin{array}{l}\text { The effect of MGL-3196 vs. placebo o achieve NASH } \\
\text { resolution on liver histology in non-cirrhotic NASH patients } \\
\text { with stage } 2 \text { or } 3 \text { fibrosis at week 52; Composite long-term } \\
\text { outcome events composed of all-cause mortality, cirrhosis, } \\
\text { and other significant liver-related events (up to } 54 \text { months) }\end{array}$ & \multicolumn{2}{|c|}{$\begin{array}{l}\text { The effect of MGL-3196 vs. placebo on the percentage changes in } \\
\text { LDL-C from baseline at week 24; The effect of MGL-3196 vs. } \\
\text { placebo to achieve improvement in fibrosis on liver histology in } \\
\text { non-cirrhotic NASH patients with stage } 2 \text { or } 3 \text { fibrosis from } \\
\text { baseline at week } 52\end{array}$} \\
\hline
\end{tabular}

H-MRS: Magnetic resonance spectroscopy; LDL-C: low-density lipoprotein cholesterol; MRI-PDFF: magnetic resonance imaging proton density fat fraction; PRO-C3: N-terminal type III collagen propeptide; NAFLD: nonalcoholic fatty liver disease; NASH: nonalcoholic steaheatitis.

\section{CONCLUSION}

The pathogenesis and progression of NAFLD is a complex and multifactorial process that involves genetic, epigenetic, and environmental factors. The heterogeneity of NAFLD has created significant challenges for discovering non-invasive biomarkers to diagnose the presence of NASH and/or to prevent or slow down its progression. The identification of homogenous patient groups based upon clinical stage, race, ethnicity, or genotype could improve the 
discovery and clinical utility of potential markers. They also could provide more specific molecular target(s) that could predict which types of compounds would be more effective for specific subgroups of patients. Nevertheless, recent data strongly suggest that targeting impaired autophagy, mitophagy, and mitochondrial function might be novel intervention strategies for NAFLD in most patients. TH is one example of a compound that can mediate these effects. It not only transcriptionally regulates genes involved in lipid, cholesterol, and glucose metabolism but also induces hepatic autophagy/lipophagy/mitophagy and mitochondrial biogenesis to increase $\beta$-oxidation of fatty acids and increase mitochondrial turnover to decrease ROS production and cellular injury. TH and its analogs are effective in treating hepatosteatosis in preclinical models and patients with NAFL. Although several promising preclinical and early clinical studies show that TH or thyromimetics can improve fibrosis in NASH, large-scale placebo-controlled Phase 3 trials need to be undertaken to confirm these findings. Nonetheless, preclinical and clinical studies thus far suggest low-dose of $\mathrm{T}_{4}$, THR $\beta 1$-selective analogs, or liver-specific thyromimetics could potentially be novel, safe, and effective therapeutic agents against NAFLD/NASH.

\section{DECLARATIONS}

\section{Authors' contributions}

Conceived the structure of the manuscript: Zhou J, Sinha RA, Yen PM

Wrote the article: Zhou J, Yen PM

Critically revised the manuscript: Sinha RA, Yen PM

Designed the table and figures and illustrated the figures: Zhou J

\section{Availability of data and materials}

Not applicable.

\section{Financial support and sponsorship}

This work was supported by the Ministry of Health $(\mathrm{MOH})$, and National Medical Research Council (NMRC), Singapore, grant number CSA19may-0002 to Yen PM, Duke-NUS Medical School and Estate of Tan Sri Khoo Teck Puat Khoo Pilot Award (Collaborative) Duke-NUS-KP (Coll)/2018/0007A to Zhou J, and Wellcome Trust/DBT India Alliance Fellowship [IA/I/16/2/502691] awarded to Sinha RA.

\section{Conflicts of interest}

All authors declared that there are no conflicts of interest.

\section{Ethical approval and consent to participate}

Not applicable.

\section{Consent for publication}

Not applicable.

\section{Copyright}

(c) The Author(s) 2021.

\section{REFERENCES}

1. Chalasani N, Younossi Z, Lavine JE, et al. The diagnosis and management of nonalcoholic fatty liver disease: practice guidance from the American Association for the Study of Liver Diseases. Hepatology 2018;67:328-57. DOI PubMed

2. Association for the Study of the Liver (EASL), European Association for the Study of Diabetes (EASD), European Association for the Study of Obesity (EASO). EASL-EASD-EASO clinical practice guidelines for the management of non-alcoholic fatty liver disease. Diabetologia 2016;59:1121-40. DOI

3. Younossi ZM, Koenig AB, Abdelatif D, Fazel Y, Henry L, Wymer M. Global epidemiology of nonalcoholic fatty liver disease-Metaanalytic assessment of prevalence, incidence, and outcomes. Hepatology 2016;64:73-84. DOI PubMed

4. Li J, Zou B, Yeo YH, et al. Prevalence, incidence, and outcome of non-alcoholic fatty liver disease in Asia, 1999-2019: a systematic 
review and meta-analysis. Lancet Gastroenterol Hepatol 2019;4:389-98. DOI PubMed

5. Younossi ZM. The epidemiology of nonalcoholic steatohepatitis. Clin Liver Dis (Hoboken) 2018;11:92-4. DOI PubMed PMC

6. Loomba R, Sanyal AJ. The global NAFLD epidemic. Nat Rev Gastroenterol Hepatol 2013;10:686-90. DOI PubMed

7. Burra P, Becchetti C, Germani G. NAFLD and liver transplantation: disease burden, current management and future challenges. JHEP Rep 2020;2:100192. DOI PubMed PMC

8. Adams LA, Anstee QM, Tilg H, Targher G. Non-alcoholic fatty liver disease and its relationship with cardiovascular disease and other extrahepatic diseases. Gut 2017;66:1138-53. DOI PubMed

9. Koo BK, Kim D, Joo SK, et al. Sarcopenia is an independent risk factor for non-alcoholic steatohepatitis and significant fibrosis. $J$ Hepatol 2017;66:123-31. DOI PubMed

10. Anstee QM, Mantovani A, Tilg H, Targher G. Risk of cardiomyopathy and cardiac arrhythmias in patients with nonalcoholic fatty liver disease. Nat Rev Gastroenterol Hepatol 2018;15:425-39. DOI PubMed

11. Taylor RS, Taylor RJ, Bayliss S, et al. Association between fibrosis stage and outcomes of patients with nonalcoholic fatty liver disease: a systematic review and meta-analysis. Gastroenterology 2020;158:1611-25.e12. DOI PubMed

12. Eslam M, Sanyal AJ, George J; International Consensus Panel. MAFLD: a consensus-driven proposed nomenclature for metabolic associated fatty liver disease. Gastroenterology 2020;158:1999-2014.e1. DOI PubMed

13. Eslam M, Newsome PN, Sarin SK, et al. A new definition for metabolic dysfunction-associated fatty liver disease: an international expert consensus statement. J Hepatol 2020;73:202-9. DOI PubMed

14. Younossi ZM, Rinella ME, Sanyal AJ, et al. From NAFLD to MAFLD: implications of a premature change in terminology. Hepatology 2021;73:1194-8. DOI PubMed

15. Singh SP, Anirvan P, Reddy KR, et al. Non-alcoholic fatty liver disease: not time for an obituary just yet! J Hepatol 2021;74:972-4. DOI PubMed

16. Lonardo A. Renaming NAFLD to MAFLD: could the LDE system assist in this transition? J Clin Med 2021;10:492. DOI PubMed PMC

17. Abada A, Elazar Z. Getting ready for building: signaling and autophagosome biogenesis. EMBO Rep 2014;15:839-52. DOI PubMed PMC

18. Dikic I, Elazar Z. Mechanism and medical implications of mammalian autophagy. Nat Rev Mol Cell Biol 2018;19:349-64. DOI PubMed

19. Gatica D, Lahiri V, Klionsky DJ. Cargo recognition and degradation by selective autophagy. Nat Cell Biol 2018;20:233-42. DOI PubMed PMC

20. Nishimura T, Tooze SA. Emerging roles of ATG proteins and membrane lipids in autophagosome formation. Cell Discov $2020 ; 6: 32$. DOI PubMed PMC

21. Singh R, Kaushik S, Wang Y, et al. Autophagy regulates lipid metabolism. Nature 2009;458:1131-5. DOI PubMed PMC

22. Kaushik S, Cuervo AM. Degradation of lipid droplet-associated proteins by chaperone-mediated autophagy facilitates lipolysis. Nat Cell Biol 2015;17:759-70. DOI PubMed PMC

23. Liu R, Lee JH, Li J, et al. Choline kinase alpha 2 acts as a protein kinase to promote lipolysis of lipid droplets. Mol Cell 2021;81:2722-2735.e9. DOI PubMed

24. Garcia-Macia M, Santos-Ledo A, Leslie J, et al. A mammalian target of rapamycin-perilipin 3 (mTORC1-Plin3) pathway is essential to activate lipophagy and protects against hepatosteatosis. Hepatology 2021. DOI PubMed

25. Schwerbel K, Kamitz A, Krahmer N, et al. Immunity-related GTPase induces lipophagy to prevent excess hepatic lipid accumulation. J Hepatol 2020;73:771-82. DOI PubMed PMC

26. Byun S, Seok S, Kim YC, et al. Fasting-induced FGF21 signaling activates hepatic autophagy and lipid degradation via JMJD3 histone demethylase. Nat Commun 2020;11:807. DOI PubMed PMC

27. Sinha RA, You SH, Zhou J, et al. Thyroid hormone stimulates hepatic lipid catabolism via activation of autophagy. J Clin Invest 2012;122:2428-38. DOI PubMed PMC

28. Lee JM, Wagner M, Xiao R, et al. Nutrient-sensing nuclear receptors coordinate autophagy. Nature 2014;516:112-5. DOI PubMed $\mathrm{PMC}$

29. Seok S, Fu T, Choi SE, et al. Transcriptional regulation of autophagy by an FXR-CREB axis. Nature 2014;516:108-11. DOI PubMed PMC

30. Farah BL, Sinha RA, Wu Y, et al. $\beta$-Adrenergic agonist and antagonist regulation of autophagy in HepG2 cells, primary mouse hepatocytes, and mouse liver. PLoS One 2014;9:e98155. DOI PubMed PMC

31. Yoo J, Jeong IK, Ahn KJ, Chung HY, Hwang YC. Fenofibrate, a PPAR $\alpha$ agonist, reduces hepatic fat accumulation through the upregulation of TFEB-mediated lipophagy. Metabolism 2021;120:154798. DOI PubMed

32. Waskowicz LR, Zhou J, Landau DJ, et al. Bezafibrate induces autophagy and improves hepatic lipid metabolism in glycogen storage disease type Ia. Hum Mol Genet 2019;28:143-54. DOI PubMed PMC

33. Zhou J, Waskowicz LR, Lim A, et al. A liver-specific thyromimetic, VK2809, decreases hepatosteatosis in glycogen storage disease type Ia. Thyroid 2019;29:1158-67. DOI PubMed PMC

34. Yavarow ZA, Kang HR, Waskowicz LR, et al. Fenofibrate rapidly decreases hepatic lipid and glycogen storage in neonatal mice with glycogen storage disease type Ia. Hum Mol Genet 2020;29:286-94. DOI PubMed PMC

35. Zhou J, Farah BL, Sinha RA, et al. Epigallocatechin-3-gallate (EGCG), a green tea polyphenol, stimulates hepatic autophagy and lipid clearance. PLoS One 2014;9:e87161. DOI PubMed PMC

36. Sinha RA, Farah BL, Singh BK, et al. Caffeine stimulates hepatic lipid metabolism by the autophagy-lysosomal pathway in mice. 
Hepatology 2014;59:1366-80. DOI PubMed

37. Ashrafi G, Schwarz TL. The pathways of mitophagy for quality control and clearance of mitochondria. Cell Death Differ 2013;20:3142. DOI PubMed PMC

38. Vringer E, Tait SWG. Mitochondria and Inflammation: cell death heats up. Front Cell Dev Biol 2019;7:100. DOI PubMed PMC

39. Chen G, Kroemer G, Kepp O. Mitophagy: an emerging role in aging and age-associated diseases. Front Cell Dev Biol 2020;8:200. DOI PubMed PMC

40. Narendra DP, Jin SM, Tanaka A, et al. PINK1 is selectively stabilized on impaired mitochondria to activate Parkin. PLoS Biol 2010;8:e1000298. DOI PubMed PMC

41. Kondapalli C, Kazlauskaite A, Zhang N, et al. PINK1 is activated by mitochondrial membrane potential depolarization and stimulates Parkin E3 ligase activity by phosphorylating Serine 65. Open Biol 2012;2:120080. DOI PubMed PMC

42. Aerts L, Craessaerts K, De Strooper B, Morais VA. PINK1 kinase catalytic activity is regulated by phosphorylation on serines 228 and 402.J Biol Chem 2015;290:2798-811. DOI PubMed PMC

43. Bakula D, Scheibye-Knudsen M. MitophAging: mitophagy in aging and disease. Front Cell Dev Biol 2020;8:239. DOI PubMed PMC

44. Liu L, Feng D, Chen G, et al. Mitochondrial outer-membrane protein FUNDC1 mediates hypoxia-induced mitophagy in mammalian cells. Nat Cell Biol 2012;14:177-85. DOI PubMed

45. Chen G, Han Z, Feng D, et al. A regulatory signaling loop comprising the PGAM5 phosphatase and CK2 controls receptor-mediated mitophagy. Mol Cell 2014;54:362-77. DOI PubMed

46. Wu W, Tian W, Hu Z, et al. ULK1 translocates to mitochondria and phosphorylates FUNDC1 to regulate mitophagy. EMBO Rep 2014;15:566-75. DOI PubMed PMC

47. González-Rodríguez A, Mayoral R, Agra N, et al. Impaired autophagic flux is associated with increased endoplasmic reticulum stress during the development of NAFLD. Cell Death Dis 2014;5:e1179. DOI PubMed PMC

48. Tanaka S, Hikita H, Tatsumi T, et al. Rubicon inhibits autophagy and accelerates hepatocyte apoptosis and lipid accumulation in nonalcoholic fatty liver disease in mice. Hepatology 2016;64:1994-2014. DOI PubMed

49. Fukuo Y, Yamashina S, Sonoue H, et al. Abnormality of autophagic function and cathepsin expression in the liver from patients with non-alcoholic fatty liver disease. Hepatol Res 2014;44:1026-36. DOI PubMed

50. Zhang H, Yan S, Khambu B, et al. Dynamic MTORC1-TFEB feedback signaling regulates hepatic autophagy, steatosis and liver injury in long-term nutrient oversupply. Autophagy 2018;14:1779-95. DOI PubMed PMC

51. Settembre C, De Cegli R, Mansueto G, et al. TFEB controls cellular lipid metabolism through a starvation-induced autoregulatory loop. Nat Cell Biol 2013;15:647-58. DOI PubMed PMC

52. Komatsu M, Waguri S, Ueno T, et al. Impairment of starvation-induced and constitutive autophagy in Atg7-deficient mice. J Cell Biol 2005;169:425-34. DOI PubMed PMC

53. Xiong X, Tao R, DePinho RA, Dong XC. The autophagy-related gene 14 (Atg14) is regulated by forkhead box O transcription factors and circadian rhythms and plays a critical role in hepatic autophagy and lipid metabolism. J Biol Chem 2012;287:39107-14. DOI PubMed PMC

54. Liu K, Zhao E, Ilyas G, et al. Impaired macrophage autophagy increases the immune response in obese mice by promoting proinflammatory macrophage polarization. Autophagy 2015;11:271-84. DOI PubMed PMC

55. Yamada T, Murata D, Adachi Y, et al. Mitochondrial stasis reveals p62-mediated ubiquitination in Parkin-independent mitophagy and mitigates nonalcoholic fatty liver disease. Cell Metab 2018;28:588-604.e5. DOI PubMed PMC

56. Ahn SB, Jang K, Jun DW, Lee BH, Shin KJ. Expression of liver X receptor correlates with intrahepatic inflammation and fibrosis in patients with nonalcoholic fatty liver disease. Dig Dis Sci 2014;59:2975-82. DOI PubMed

57. Kim YS, Nam HJ, Han CY, et al. Liver X receptor alpha activation inhibits autophagy and lipophagy in hepatocytes by dysregulating autophagy-related 4B cysteine peptidase and Rab-8B, reducing mitochondrial fuel oxidation. Hepatology 2021;73:1307-26. DOI PubMed

58. Nguyen TTP, Kim DY, Lee YG, et al. SREBP-1c impairs ULK1 sulfhydration-mediated autophagic flux to promote hepatic steatosis in high-fat-diet-fed mice. Mol Cell 2021;81:3820-32.e7. DOI PubMed

59. Lee DH, Park SH, Ahn J, et al. Mir214-3p and Hnf4a/Hnf4 $\alpha$ reciprocally regulate Ulk1 expression and autophagy in nonalcoholic hepatic steatosis. Autophagy 2021;17:2415-31. DOI PubMed PMC

60. He A, Chen X, Tan M, et al. Acetyl-CoA derived from hepatic peroxisomal $\beta$-oxidation inhibits autophagy and promotes steatosis via mTORC1 activation. Mol Cell 2020;79:30-42.e4. DOI PubMed PMC

61. Zhang Z, Qian Q, Li M, et al. The unfolded protein response regulates hepatic autophagy by sXBP1-mediated activation of TFEB. Autophagy 2021;17:1841-55. DOI PubMed PMC

62. Park HS, Song JW, Park JH, et al. TXNIP/VDUP1 attenuates steatohepatitis via autophagy and fatty acid oxidation. Autophagy 2021;17:2549-64. DOI PubMed PMC

63. Wu X, Poulsen KL, Sanz-Garcia C, et al. MLKL-dependent signaling regulates autophagic flux in a murine model of non-alcoholassociated fatty liver and steatohepatitis. J Hepatol 2020;73:616-27. DOI PubMed PMC

64. Liu K, Qiu D, Liang X, et al. Lipotoxicity-induced STING1 activation stimulates MTORC1 and restricts hepatic lipophagy. Autophagy 2021:1-17. DOI PubMed

65. Braun D, Schweizer U. Thyroid hormone transport and transporters. Vitam Horm 2018;106:19-44. DOI PubMed

66. DeMartino GN, Goldberg AL. Thyroid hormones control lysosomal enzyme activities in liver and skeletal muscle. Proc Natl Acad Sci U S A 1978;75:1369-73. DOI PubMed PMC 
67. Peeters RP, Visser TJ. Metabolism of thyroid hormone. Endotext. South Dartmouth (MA); 2000.

68. Anyetei-Anum CS, Roggero VR, Allison LA. Thyroid hormone receptor localization in target tissues. J Endocrinol 2018;237:R1934. DOI PubMed PMC

69. Feng X, Jiang Y, Meltzer P, Yen PM. Thyroid hormone regulation of hepatic genes in vivo detected by complementary DNA microarray. Mol Endocrinol 2000;14:947-55. DOI PubMed

70. Sinha RA, Singh BK, Yen PM. Thyroid hormone regulation of hepatic lipid and carbohydrate metabolism. Trends Endocrinol Metab 2014;25:538-45. DOI PubMed

71. Sinha RA, Singh BK, Yen PM. Direct effects of thyroid hormones on hepatic lipid metabolism. Nat Rev Endocrinol 2018;14:259-69. DOI PubMed PMC

72. Sinha RA, Bruinstroop E, Singh BK, Yen PM. Nonalcoholic fatty liver disease and hypercholesterolemia: roles of thyroid hormones, metabolites, and agonists. Thyroid 2019;29:1173-91. DOI PubMed PMC

73. Coates PM, Hoffman GM, Finegold DN. Effect of thyroid hormones on human mononuclear leukocyte lysosomal acid lipase activity. J Clin Endocrinol Metab 1982;54:559-62. DOI PubMed

74. Sinha RA, Singh BK, Zhou J, et al. Thyroid hormone induction of mitochondrial activity is coupled to mitophagy via ROS-AMPKULK1 signaling. Autophagy 2015;11:1341-57. DOI PubMed PMC

75. Singh BK, Sinha RA, Tripathi M, et al. Thyroid hormone receptor and ERR $\alpha$ coordinately regulate mitochondrial fission, mitophagy, biogenesis, and function. Sci Signal 2018;11:eaam5855. DOI PubMed

76. Kim J, Kundu M, Viollet B, Guan KL. AMPK and mTOR regulate autophagy through direct phosphorylation of Ulk1. Nat Cell Biol 2011;13:132-41. DOI PubMed PMC

77. Egan DF, Shackelford DB, Mihaylova MM, et al. Phosphorylation of ULK1 (hATG1) by AMP-activated protein kinase connects energy sensing to mitophagy. Science 2011;331:456-61. DOI PubMed PMC

78. Tian W, Li W, Chen Y, et al. Phosphorylation of ULK1 by AMPK regulates translocation of ULK1 to mitochondria and mitophagy. FEBS Lett 2015;589:1847-54. DOI PubMed

79. Lesmana R, Sinha RA, Singh BK, et al. Thyroid hormone stimulation of autophagy is essential for mitochondrial biogenesis and activity in skeletal muscle. Endocrinology 2016;157:23-38. DOI PubMed

80. Chen W, Roeder RG. Mediator-dependent nuclear receptor function. Semin Cell Dev Biol 2011;22:749-58. DOI PubMed PMC

81. Zhou J, Singh BK, Ho JP, et al. MED1 mediator subunit is a key regulator of hepatic autophagy and lipid metabolism. Autophagy 2021:1-19. DOI PubMed

82. Yuan CX, Ito M, Fondell JD, Fu ZY, Roeder RG. The TRAP220 component of a thyroid hormone receptor- associated protein (TRAP) coactivator complex interacts directly with nuclear receptors in a ligand-dependent fashion. Proc Natl Acad Sci U S A 1998;95:7939-44. DOI PubMed PMC

83. Tseng YH, Ke PY, Liao CJ, et al. Chromosome 19 open reading frame 80 is upregulated by thyroid hormone and modulates autophagy and lipid metabolism. Autophagy 2014;10:20-31. DOI PubMed PMC

84. Iannucci LF, Cioffi F, Senese R, et al. Metabolomic analysis shows differential hepatic effects of $\mathrm{T}_{2}$ and $\mathrm{T}_{3}$ in rats after short-term feeding with high fat diet. Sci Rep 2017;7:2023. DOI PubMed PMC

85. Swanson KV, Deng M, Ting JP. The NLRP3 inflammasome: molecular activation and regulation to therapeutics. Nat Rev Immunol 2019;19:477-89. DOI PubMed PMC

86. Hafner-Bratkovič I, Pelegrín P. Ion homeostasis and ion channels in NLRP3 inflammasome activation and regulation. Curr Opin Immunol 2018;52:8-17. DOI PubMed

87. Mridha AR, Wree A, Robertson AAB, et al. NLRP3 inflammasome blockade reduces liver inflammation and fibrosis in experimental NASH in mice. $J$ Hepatol 2017;66:1037-46. DOI PubMed PMC

88. Zhong Z, Umemura A, Sanchez-Lopez E, et al. NF- $\mathrm{kB}$ restricts inflammasome activation via elimination of damaged mitochondria. Cell 2016;164:896-910. DOI PubMed PMC

89. Biasizzo M, Kopitar-Jerala N. Interplay between NLRP3 inflammasome and autophagy. Front Immunol 2020;11:591803. DOI PubMed PMC

90. Vargas R, Videla LA. Thyroid hormone suppresses ischemia-reperfusion-induced liver NLRP3 inflammasome activation: role of AMP-activated protein kinase. Immunol Lett 2017;184:92-7. DOI PubMed

91. der Spek AH, Fliers E, Boelen A. Thyroid hormone metabolism in innate immune cells. J Endocrinol 2017;232:R67-81. DOI

92. De Luca R, Davis PJ, Lin HY, et al. Thyroid hormones interaction with immune response, inflammation and non-thyroidal illness syndrome. Front Cell Dev Biol 2020;8:614030. DOI PubMed PMC

93. Forini F, Nicolini G, Kusmic C, et al. Integrative analysis of differentially expressed genes and miRNAs predicts complex T3mediated protective circuits in a rat model of cardiac ischemia reperfusion. Sci Rep 2018;8:13870. DOI PubMed PMC

94. Chen Y, Yuan M, Xia M, Wang L, Zhang Y, Li PL. Instant membrane resealing in nlrp3 inflammmasome activation of endothelial cells. Front Biosci (Landmark Ed) 2016;21:635-50. DOI PubMed PMC

95. Wang Y, Men M, Yang W, Zheng H, Xue S. MiR-31 Downregulation protects against cardiac ischemia/reperfusion injury by targeting protein kinase C epsilon (PKCE) directly. Cell Physiol Biochem 2015;36:179-90. DOI PubMed

96. de Castro AL, Fernandes RO, Ortiz VD, et al. Thyroid hormones decrease the proinflammatory TLR4/NF- $\kappa \beta$ pathway and improve functional parameters of the left ventricle of infarcted rats. Mol Cell Endocrinol 2018;461:132-42. DOI PubMed

97. Furuya F, Ishii T, Tamura S, et al. The ligand-bound thyroid hormone receptor in macrophages ameliorates kidney injury via inhibition of nuclear factor-kB activities. Sci Rep 2017;7:43960. DOI PubMed PMC

98. Pagadala MR, Zein CO, Dasarathy S, Yerian LM, Lopez R, McCullough AJ. Prevalence of hypothyroidism in nonalcoholic fatty liver 
disease. Dig Dis Sci 2012;57:528-34. DOI PubMed PMC

99. Kim D, Kim W, Joo SK, Bae JM, Kim JH, Ahmed A. Subclinical hypothyroidism and low-normal thyroid function are associated with nonalcoholic steatohepatitis and fibrosis. Clin Gastroenterol Hepatol 2018;16:123-31.e1. DOI PubMed

100. Chung GE, Kim D, Kim W, et al. Non-alcoholic fatty liver disease across the spectrum of hypothyroidism. J Hepatol 2012;57:150-6. DOI PubMed

101. Bano A, Chaker L, Plompen EP, et al. Thyroid function and the risk of nonalcoholic fatty liver disease: the rotterdam study. $J$ Clin Endocrinol Metab 2016;101:3204-11. DOI PubMed

102. Bohinc BN, Michelotti G, Xie G, et al. Repair-related activation of hedgehog signaling in stromal cells promotes intrahepatic hypothyroidism. Endocrinology 2014;155:4591-601. DOI PubMed PMC

103. Bruinstroop E, Dalan R, Cao Y, et al. Low-dose levothyroxine reduces intrahepatic lipid content in patients with type 2 diabetes mellitus and NAFLD. J Clin Endocrinol Metab 2018;103:2698-706. DOI PubMed

104. Bruinstroop E, Zhou J, Tripathi M, et al. Early induction of hepatic deiodinase type 1 inhibits hepatosteatosis during NAFLD progression. Mol Metab 2021;53:101266. DOI PubMed PMC

105. Tahara K, Akahane T, Namisaki T, et al. Thyroid-stimulating hormone is an independent risk factor of non-alcoholic fatty liver disease. JGH Open 2020;4:400-4. DOI PubMed PMC

106. Manka P, Bechmann L, Best J, et al. Low free triiodothyronine is associated with advanced fibrosis in patients at high risk for nonalcoholic steatohepatitis. Dig Dis Sci 2019;64:2351-8. DOI PubMed

107. Yu G, Tzouvelekis A, Wang R, et al. Thyroid hormone inhibits lung fibrosis in mice by improving epithelial mitochondrial function. Nat Med 2018;24:39-49. DOI PubMed PMC

108. Alonso-Merino E, Martín Orozco R, Ruíz-Llorente L, et al. Thyroid hormones inhibit TGF- $\beta$ signaling and attenuate fibrotic responses. Proc Natl Acad Sci U S A 2016;113:E3451-60. DOI PubMed PMC

109. Harrison SA, Bashir MR, Guy CD, et al. Resmetirom (MGL-3196) for the treatment of non-alcoholic steatohepatitis: a multicentre, randomised, double-blind, placebo-controlled, phase 2 trial. Lancet 2019;394:2012-24. DOI PubMed

110. Erion MD, Cable EE, Ito BR, et al. Targeting thyroid hormone receptor-beta agonists to the liver reduces cholesterol and triglycerides and improves the therapeutic index. Proc Natl Acad Sci U S A 2007;104:15490-5. DOI PubMed PMC

111. Fujitaki JM, Cable EE, Ito BR, et al. Preclinical pharmacokinetics of a HepDirect prodrug of a novel phosphonate-containing thyroid hormone receptor agonist. Drug Metab Dispos 2008;36:2393-403. DOI PubMed

112. Cable EE, Finn PD, Stebbins JW, et al. Reduction of hepatic steatosis in rats and mice after treatment with a liver-targeted thyroid hormone receptor agonist. Hepatology 2009;49:407-17. DOI PubMed

113. Loomba R, Neutel J, Mohseni R, et al. LBP-20-VK2809, a Novel Liver-Directed Thyroid Receptor Beta Agonist, Significantly Reduces Liver Fat with Both Low and High Doses in Patients with Non-Alcoholic Fatty Liver Disease: A Phase 2 Randomized, Placebo-Controlled Trial. J Hepatol 2019;70:e150-1. DOI 